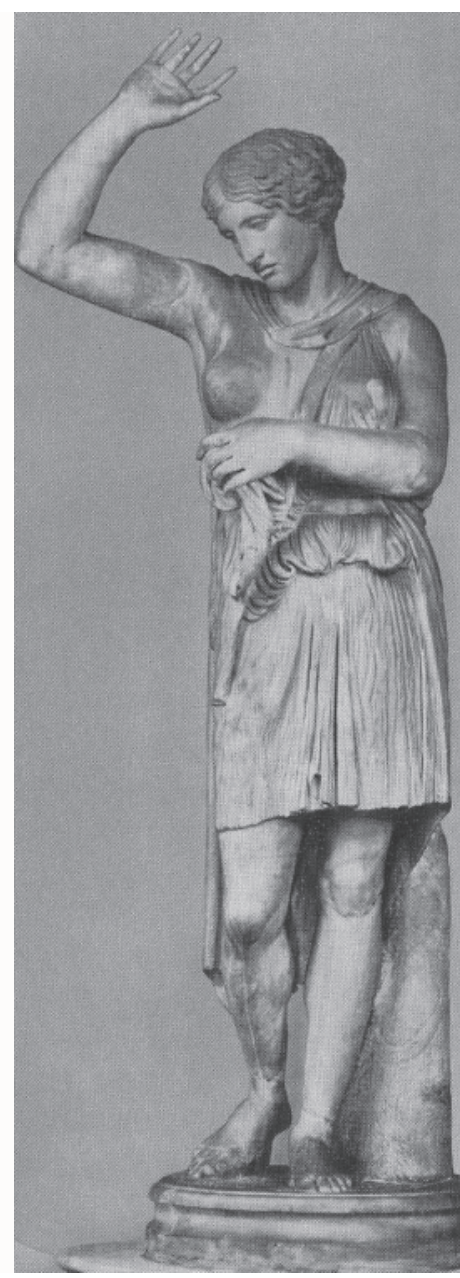

\section{Und sie schämeten sich nicht}

Früher, als noch vieles möglich war, hatten die Frauen Flügel, waren Göttinnen, hießen Nike, flatterten von Sieg zu Sieg. Oder sie hatten den bösen Blick wie Gorgo, die Meduse. Oder Lust auf rohes Fleisch wie die Mänaden. Und es war nicht übel gefährlich, in einen Schwarm Amazonen zu geraten, die vor nichts zurückschreckten, die sich sogar die rechte Brust abgeschnitten oder ausgebrannt haben sollen, nur um Pfeil und Bogen männlicher anlegen zu können. Von linkshändigen Amazonen ist ja nichts überliefert. Wie Pentheus seinerzeit von der femininen Hetztruppe des Dionysos durch die Wälder gejagt und zur Strecke gebracht worden ist, das war schon

Zum Autor: Hans-Joachim Müller

- Studium der Philosophie und

Kunstgeschichte in Freiburg i. Br.

- langjähriger Mitarbeiter im

Feuilleton der ZEIT

- zuletzt Feuilletonchef und

Mitglied der Redaktionsleitung

der Basler Zeitung

- lebt heute als freier Autor

(FAZ, ZEIT, NZZ, art-Magazin) in

Freiburg und in Süditalien. ein starkes Stück. Man stellt doch mit einiger Erleichterung fest, dass der Spuk vorbei scheint, die wilden Weiber Haustiere geworden und seither nie mehr beim Abschneiden und Ausbrennen beobachtet worden sind.

Typisch freilich, dass die seltsamen Selbst- und Fremdverletzungen nur außerparadiesisch belegt sind. Könnte man sich unsere Eva so drastisch vorstellen? Stammt sie doch aus schlafendem, also rundum friedlichem Männermaterial. Dass die Scholastik der Männin als gleichsam Nachgeborener nicht viel zutrauen wollte, hat die Pointe der Geschichte allemal schmählich verkannt. In Wahrheit geht es weder um die pole position noch um hintere Ränge, sondern um eine offensichtlich notwendig gewordene Nachbesserung, eine bedenkenswerte Schöpfungskorrektur.

Der genetische Siebentageplan erwies sich eben doch nicht als so vollkommen, wie er nach den Gesetzen reiner Metaphysik hätte sein sollen. Da können die Kreationisten aller Länder noch so leidenschaftlich gegen Darwins Nachkommenschaft wüten, die entscheidende Stelle haben sie immer überlesen. Hier, ganz vorne im Bibelbuch, wird nämlich nichts anderes berichtet als vom Beginn der Evolution. Der Schöpfer gestattet sich bei der Nachschöpfung kleine Ungenauigkeiten, hält sich - aus Zufall oder Notwendigkeit, wer weiß - einmal nicht so exakt an die Adamsmatrize. Und schon ist es passiert. Unten rum und oben rum alles anders, alles neu.

Dass sich die morphologischen Unterschiede alsbald als ausgesprochen nützlich herausstellten, ist das eine. Das andere aber doch, dass nun beide eine Freude aneinander hatten, sich partout nicht schämen wollten, und niemand an Abschneiden und Ausbrennen dachte. Wohl wahr, noch immer gibt Adam den Rippenbogen als empfindliche Stelle an. Und kardiologisch gesehen ist dem Mann das Risiko geblieben, das er mit der ersten nachschöpfungsbedingten Anästhesie eingegangen ist. Er sollte also weniger rauchen, sollte mehr Sport treiben, Mineralwässerchen trinken und Evas fruktalen Bestimmqualitäten grundsätzlich misstrauen.

Ansonsten hätte sich nicht viel zu ändern brauchen. Aber lassen wir das Lamentieren. Als alles aus dem Ruder lief und gar der letzte Sinn aus der Weltgeschichte schwand, sah man die beiden noch immer nicht in Hose und Rock. Ohne Ausnahme lassen alle Bilddokumente aus dem Garten Eden allenfalls wilden Knöterich um Evas und Adams Hüfte ranken, während im Brustbereich die Gestaltlaunen hübsch sichtbar bleiben. Das nennen wir den Trost der 
Kunst. Kein noch so drohender Goldzeitalterverlust hält uns davon ab, aus dem Stückwerk der Schöpfung ästhetisches Kapital zu schlagen.

Zwar haben sich postparadiesisch die Ober- und Unterleiber beidgeschlechtlich verhüllt, und mancherlei praktische und sittliche Erwägung sorgt dafür, dass sich daran nichts grundsätzlich ändert. Aber die Bilder tun noch immer so, als erwachte Adam aus seiner Betäubung und sähe nun zum ersten Mal, welcher Liebreiz aus der widerrechtlichen Gewebeentnahme geworden ist. Nach all dem wird man eine gewisse Busenfixierung dem Urmenschen in uns wohl attestieren müssen. Und dagegen lässt sich eigentlich nicht viel sagen, wie man ja auch gegen einen Jahrhundertsommer keine wirklich überzeugenden Einwände vorbringen kann.

Die Folgen sind bekannt. Paris, stadtbekannter Schnösel aus Troja, sollte am Berg Ida letztinstanzlich bestimmen, wer unter den drei Olympierinnen die Schönste ist. Hera, die Spitzengöttin, Athene, die Unbesiegbare, Aphrodite, das Busenwunder. Dem Mann ward Weltherrschaft und Schlachtenglück versprochen. Er entschied sich fürs Bett. Was ihn durchaus sympathisch macht, aber politische Verwicklungen mit sich brachte, denen gegenüber der Fehlapfel an den Flüssen Pison, Gihon, Hiddekel und Euphrat sich wie eine Bagatelle ausnimmt.

Es sollte furchtbar werden. Helme zertrümmert, Gliedmassen zerschlagen, ganze Kulturen ausgelöscht, der Himmel in Aufruhr, und als Odysseus endlich wieder in Ithaka war, musste er erst noch eine Hausschlachtung befehligen, um ans lang entbehrte Beilager zu gelangen. Da dachte sich Adam, bevor er nun chronische Schmerzen am Rippenbogen bekäme, wäre vielleicht doch einmal ein Busenopfer angebracht. Und so sind den schönen Bildern immer auch ein paar schlechte Träume beigemischt. Die schlechtesten stammen aus der Spätantike, als aus Christentum und Christenverfolgung ein ganzes Heer von Mustermenschen erwuchs. Agathe, die Gute, zum Beispiel. Schöne Tochter vornehmer
Eltern aus Catania. Quintianus, der Statthalter, hat ein Auge auf sie geworfen. Sie ziert sich. Christin, nix Liebe. Nicht einmal im Zwangspuff ist mit ihr etwas anzufangen. Also Verrat, Prozess, Martyrium. Brüste abgeschnitten, Brüste ausgebrannt, spitze Scherben, glimmende Kohlen. Am 5. Februar des Jahres 252 wird sie zu Grabe getragen. Und die glühende Verehrung, die alsbald anhebt, zahlt sich aus. Wenn der Ätna wieder spuckt, lenkt die Heilige die Lavaströme um und ist überhaupt bei Feuersnot schneller zur Stelle als der Wagen der Vigili del fuoco. In der Zeit der christenfrommen Kunst haben die Maler Agathen gerne mit einem Teller dargestellt, auf dem sie ihre malträtierten Attribute wie ein Hausmittel zur Brandbekämpfung präsentiert. Das sieht nicht fein aus, mammografisch nüchtern. Und wenn Adam daran denkt, wie es war, als er aus seiner Betäubung erwachte und sah, welcher Liebreiz aus der widerrechtlichen Gewebeentnahme geworden ist, dann verwünscht er mit der medizinischen Indikation doch gleich die ganze silikonverstärkte Moderne.

Moderne ist, wenn man nicht mehr weiß, wie man die schlechten Träume wieder loswird, wie man die schönen Bilder erinnert. Die Antike hat es noch gewusst. In Ephesos gab es mal einen Wettbewerb für die besten griechischen Bildhauer. Thema: die verwundete Amazone. Das wilde Weib als Opferfrau, als Schmerzensfrau, als anrührendes Bild ihrer tödlichen Domestizierung. Phidias, Polyklet, Kresilas, Phradmon, all die Cracks des 5. Jahrhunderts haben mitgemacht, und Generationen von Kopisten werden die verlorenen griechischen Bronzen in römischem Marmor nachschaffen. Eine steht im kapitolinischen Museum in Rom. Mit der linken Hand hat die waffenlose Kämpferin das ziemlich durchsichtige Gewand von der Schulter gezogen. Dort, unterhalb der Brust hat der Speer sie getroffen - am empfindlichen Rippenbogen. Adam sieht's mit Mitleid und Genugtuung.

Hans-Joachim Müller

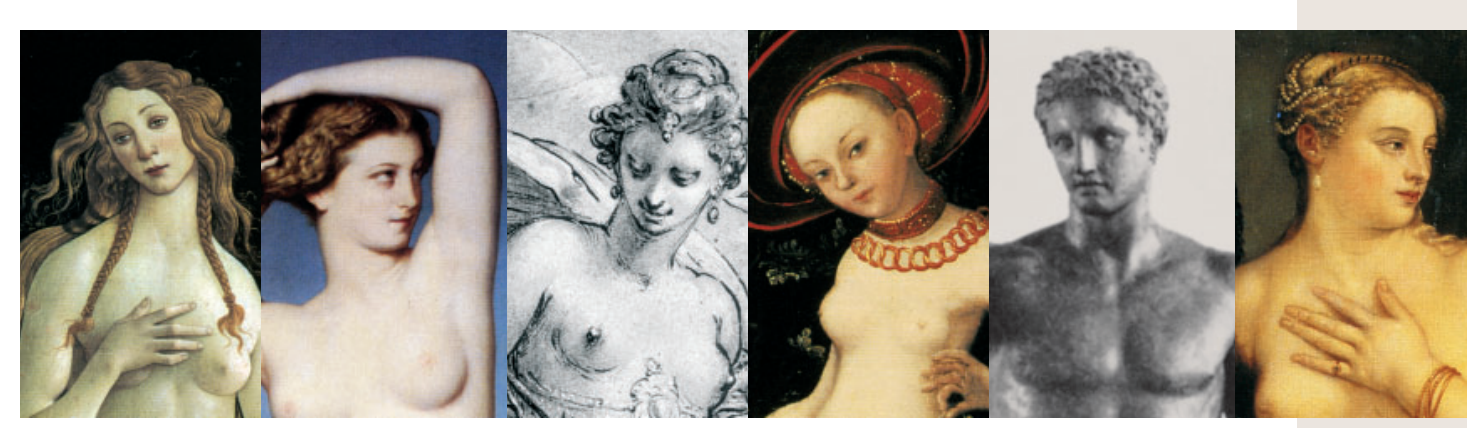

